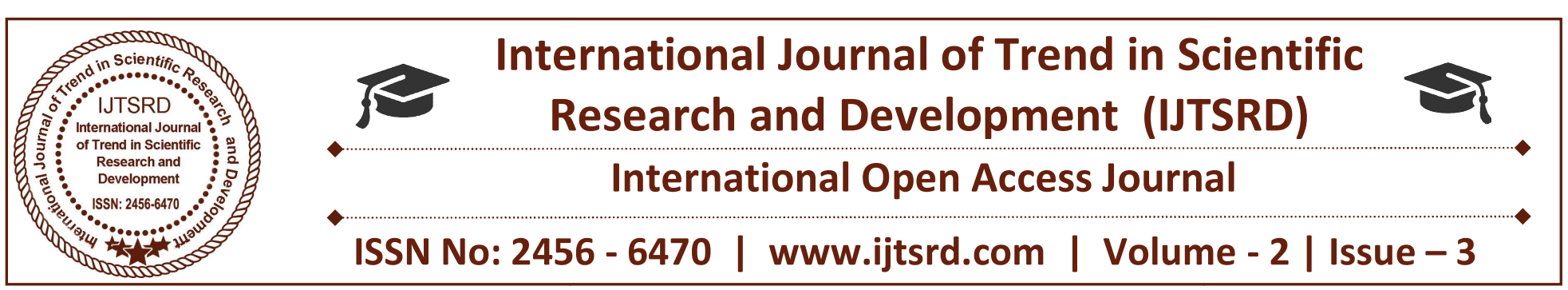

\title{
The Significance of applying Recent Trends and New Technologies in reconstructing the Ancient History of Tamilnadu
}

\author{
Dr. E. Iniyan \\ M.A., Ph.D., Assistant Professor of Archaeology, School of History and Tourism Studies, \\ Tamil Nadu Open University, Saidapet, Chennai, Tamil Nadu, India
}

\begin{abstract}
This article picture's about various technological sources that helps us in tracing the ancient history of Tamil country which were already in existence in the archaeological research field all over the world. These advanced technologies shows how the prolongation of the ancient society had shaped and attained its present status and also helps us to know about the ancient tamil society how well it is civilized and highly cultured when compared with the other ancient societies of the rest of the world. In this paper the technological aspects such as X-Ray Fluorescence (XRF) Analysis, Airborne Laser scanning (Lidar), Microbial Technology, Remote Sensing, Laser Cleaning (Graffiti cleaning), Terrestrial laser scanning, Resistivity Meters, Magnetometers, Ground Penetrating Radar, X-ray topography, Laser treatment (cleaning pollution), NDE methods, Drone, X-Radiography, X-ray guns has been considered for presentation and dealt in elaborative manner how these technologies can shape the future archaeological research in the state.
\end{abstract}

Reconstructing the history of ancient society with the use of archaeological sources by correlating with various disciplines is called as historical research. From the beginning of the Early stone age period, ancient Tamil country had witnessed various changes in the environment and climate and the man who lived a nomadic life had slowly and steadily started adapting those environmental changes and also made himself more conducive to live with that changes. The adaptation of new technologies by early humans had begun in the early stone age period itself when the man came to know the idea of manufacturing stone tools and creating fire for the purpose of preparing food by tearing the tubers, cutting the branches of trees and killing the animals for meat. Later, after the identification of metal ores more particularly in Tamilnadu the Iron ore, the manufacture of different type of tools used for the purpose of agriculture and domestic activity had resulted in the development of economic and social status of the people. The manufacture of different types of potteries by various methods has helped the society in the day to day domestic usage. Many semiprecious stones, glass and terracotta beads which were also identified from various sites shows the existence of different industries in the ancient Tamil country. It is known that the next invention of technology by man was the discovery of Script. Different materials and techniques were employed for the purpose of writing the script. Another technological development that emerged in the ancient Tamil county after the emergence of kingship was the manufacture of coins, made out of different raw materials with different shapes and designs belonging to various dynasties, local chieftains, etc.

Now, in the present day context we must be aware of the new technologies which were very helpful in reconstructing the ancient history of Tamil country. With the help of this, we should know how the ancient society had gradually attained its development and had learned how to change the lifestyle and to adapt the new technologies for its survival. Science is the main subject which plays a major role in the reconstruction of ancient history as the archaeological sources are subjected to the 
scientific researches which includes different new technologies for reaching the accurate dates of the different cultural periods. Correlation of archaeological sources with different scientific disciplines like chemistry, zoology, botany, physics, geology and other social science and arts disciplines like anthropology, literature i.e. Sangam Literature, will help us to reach out the nearest dates of the materials that were identified from exploration and excavations done at various archaeological sites.

This article picture's about various technological sources that helps us in tracing the ancient history of Tamil country which were already in existence in the archaeological research field all over the world. These advanced technologies shows how the prolongation of the ancient society had shaped and attained its present status and also helps us to know about the ancient tamil society how well it is civilized and highly cultured when compared with the other ancient societies of the rest of the world. In this paper the technological aspects such as X-Ray Fluorescence (XRF) Analysis, Airborne Laser scanning (Lidar), Laser Cleaning (Graffiti cleaning), Terrestrial laser scanning, Resistivity Meters, Magnetometers, Ground Penetrating Radar, X-ray topography, Laser treatment (cleaning pollution), NDE methods, Drone, X-Radiography, X-ray guns has been considered for presentation and dealt in elaborative manner how these technologies can shape the future archaeological research in the state.

\section{X-Ray Fluorescence (XRF) Analysis}

An X-ray fluorescence (XRF) spectrometer is an $\mathrm{X}$ ray instrument used for routine, relatively nondestructive chemical analyses of rocks, minerals, sediments and fluids. It works on wavelengthdispersive spectroscopic principles that are similar to an electron probe micro-analyser (EPMA). This analysis method cannot generally make analyses on the smaller size of EPMA work (2-5 microns), rather it is typically used for bulk analyses of larger fractions of geological materials. The easy handling and low cost of sample preparation, and the stability and easy use of $\mathrm{x}$-ray spectrometers make this one as the most widely used methods for analysis of major and trace elements in rocks, minerals, and sediment. The chemical compositions of rocks are used to solve numerous geological problems, including crystallization history of igneous bodies such as granite or basalt, processes of formation of the sea floor, nature of chemical weathering in various climates, stratigraphic correlation of sedimentary and volcanic rocks, processes of ore generation, and many others. ${ }^{1}$

The stratigraphy of the state shows the succession of various rocks types like Cenozoic, Mesozoic, Palaeozoic, and Proterozoic, Archaean in Tamil Nadu. Precambrian rocks with mineral assemblages of high temperature and pressure are well exposed in Tamil Nadu. A variety of older rocks (acid, basic and alkaline) have interacted with the preexisting rocks, resulting in the formation of new rock types with large variations. Crystalline rocks of Archaean to late Proterozoic age occupy over $80 \%$ of the area of the state, while the rest is covered by Phanerozoic sedimentary rocks mainly along the coastal belt and in a few inland River valleys. The hard rock terrain comprises predominantly of Charnockite and Khondalite groups and their migmatitic derivatives, supracrustal sequences of Sathyamangalam and Kolar groups and Peninsular Gneissic Complex (Bhavani Group), intruded by ultramafic-mafic complexes, basic dykes, granites and syenites. The sedimentary rocks of the coastal belt include fluviatile, fluvio-marine and marine sequences, such as Gondwana Supergroup (Carboniferous to Permian and Upper Jurassic to Lower Cretaceous), marine sediments of Cauvery basin (Lower Cretaceous to Paleogene), Cuddalore 1 Panambarai Formation (Mio-Pliocene) and sediments of Quaternary and Recent age.

The use of X-ray fluorescence in the research of Pre and Proto-Historic culture of Tamilnadu and its rock formation is a major development in the technology to expose the antiquity of prehistoric caves and tools and Megalithic burial monuments which were constructed out of huge boulders. The analysis of major and trace elements in geological materials by $\mathrm{x}$-ray fluorescence is made possible by the behavior of atoms when they interact with radiation. When materials are excited with high-energy, short wavelength radiation (e.g., X-rays), they can become ionized. If the energy of the radiation is sufficient to dislodge a tightly-held inner electron, the atom becomes unstable and an outer electron replaces the missing inner electron ${ }^{2}$. When this happens, energy is 
released due to the decreased binding energy of the inner electron orbital compared with an outer one. The emitted radiation is of lower energy than the primary incident $\mathrm{X}$-rays and is termed fluorescent radiation. Because the energy of the emitted photon is characteristic of a transition between specific electron orbitals in a particular element, the resulting fluorescent X-rays can be used to detect the abundances of elements that are present in the sample. When the X-ray fluorescence analysis is used in the research of igneous, sedimentary, and metamorphic petrology, soil surveys, mining in Tamilnadu, it makes it easy for an archaeologist to get to know about the rock formation and how far the rocks were converted into tools and the techniques implied on them to procure them. This analysis also provides the researcher a wide range of knowledge about the geological arena of Tamilnadu and its role in shaping the archaeological history of the state. The results of the research on the basis of this analysis would enhance the interest and inspire the scholars of other disciplines to have a comparative study with the archaeological studies and also on the ancient history of the state which would also lead them to discover the ancient settlements, artefacts and more sites.

\section{Airborne Laser scanning (Lidar)}

Lidar (also called LIDAR, LiDAR, and LADAR) is a surveying method that measures distance to a target by illuminating that target with a pulsed laser light, and measuring the reflected pulses with a sensor. Differences in laser return times and wavelengths can then be used to make digital 3D-representations of the target. The name lidar, sometimes considered an acronym of Light Detection And Ranging ${ }^{3}$ (sometimes Light Imaging, Detection, And Ranging), was originally a portmanteau of light and radar. Lidar has many uses in archaeology, including planning of field campaigns, mapping features under forest canopy, and overview of broad, continuous features indistinguishable from the ground ${ }^{4}$. Lidar can produce high-resolution datasets quickly and cheaply. Lidar-derived products can be easily integrated into a Geographic Information System (GIS) for analysis and interpretation.

Lidar has many applications in the field of archaeology including aiding in the planning of field campaigns, mapping features beneath forest canopy, and providing an overview of broad, continuous features that may be indistinguishable on the ground. Lidar can also provide archaeologists with the ability to create high-resolution digital elevation models (DEMs) of archaeological sites that can reveal microtopography that are otherwise hidden by vegetation. Lidar-derived products can be easily integrated into a Geographic Information System (GIS) for analysis and interpretation. It is broadly accepted as a basic source of extensive and detailed topographic data and is widely used to promote the integrated study of past and present land use and landscape modification in archaeology. ${ }^{5}$

Tamilnadu comprises of innumerous number of archaeological sites which are not exposed as they are seen confined and buried inside the deep vegetated areas (Megaliths in Nilgiris, Kollimalai, Yercaud, Javadi hill etc) which consists of countless number of burial monuments that were unexposed due to their presence in the dense forest area. In such situations, the method for the classification of ALS point cloud data to remove vegetation and reveal the 'bare earth' and traces of archaeologically relevant topography will be very much helpful to discover material remains and artefacts which are seen buried under the earth. This technology may also be used to identify the habitational debris in the sites which were seen scattered allover Tamilnadu, but been unnotified for years. In the megalithic burial monuments sites of Tamilnadu the use of Lidar would play a prominent role as the boulders could be highlighted in the digital model which will aid us in the visual interpretation of topography and surface features with the other sites present outside Tamilnadu, which can help us in dating the stone materials and to arrive for the reasonable dates for the sites. Another most important and promising factor in Lidar is Point Cloud Data, as archaeologists use it to study increasingly complex remains and landscape areas. Point Cloud Data is the developed segment that comes out of the Digital Terrain Model (DTM) and Digital Surface Model (DSM) which were the native formats of ALS. In many cases the visualization based on the DTM and DSM represent the best choice for interpretive work, as features appearing in them look somewhat familiar to those with experience reading aerial imagery or topographic maps. Point Cloud Data will be useful in the areas where standing structures in overgrown 
areas, particularly where these structures have multiple parts, e.g. a ruined castle or farmstead.

Any archaeological feature recognized in ALS data is viewed in the context of the contemporary landscape, and the impacts of current or recent land use are often abundantly apparent. The effect of mechanized agriculture, in particular deep ploughing which expose the buried ceramics and building materials to the surface creates a golden age for field survey, which results in causing evident deterioration to topographic features. As far as Tamilnadu is concerned the ALS can be used to look not just at a single feature or collection of features, but to tie more closely together the features and the landscape in which they are embedded. Air borne laser scanning could be used in the archaeological projects which study the phenomenon of urbanism in densely forested areas at present in Tamilnadu, which would result in good understanding of the structure of the cities of the states. The scale of urbanized areas in the state would be a easy and effective task to grasp with the use of Lidar, which would have been a difficult aspect in the past, because of the poor visibility and difficulties of accessibility on the ground in dense jungle environments. The methodology used to analyze and interpret ALS data has matured, and the general approach is now widely agreed upon. Archaeology is seeing a rapid democratization of the use of this data, and methodological development to treat difficult landscapes or classes of features continues as the use of ALS proliferates in the western countries. The greatest impacts of ALS are that by allowing archaeologists to more efficiently survey the state obscured by woodland or scrub vegetation, ALS could reintegrate these areas into research based on regional survey data, which can open forests to systematic study resulting the exposure of more archaeological remains and artifacts which initially paves way for a researcher to get more concentration on the subject concerned.

\section{Geophysics}

The geophysical imaging techniques applied to archaeology are acquiring a growing weight in the archaeological projects globally. The use of geophysical surveys to delimitate, describe or image cultural remains at low costs and in a non-destructive way allowed conceiving archaeological projects in a different way. On the one hand, archaeological geophysics had dramatically enhanced the real area covered by a single project, helping archaeologists to explore large areas and to understand the sites in wider points of view, and not only by the material objects or remains. On the other hand, the information obtained in a single survey allows archaeologists to select the location of their excavation with previous information that helps optimizing their resources and increase the effectiveness of excavations. In the part of Landscape archaeology is concerned with the help of the combination of aerial and satellite multi spectral imagery, geophysics can be applied to study large areas of lands like Adhichanallur which is a iron age composite site nearer to which the habitation site must have been available, which is not yet traced for further research. So the use of geophysical techniques would have a great impact in the archaeological research in the state. The use of geophysical techniques gives us the possibility to explore the complete area of the site and have a clear delimitation of remains and is definitely a better way to take decisions about where to dig and why to do it. The megalithic assemblage in Tamilnadu is seen scattered in every corner of the state, but without complete survey concentrated on them. So using the geophysical techniques would be a very good task to expose the then existed society in the region. In the case of habitation sites, they are discovered in equal number when compared with burial monuments and surveying those areas for delimiting them to conduct excavation in the spot where we could unearth archaeological remains through which the sociocultural aspects of the particular region and the society of the contemporary culture and the way the society flourished could be accessed. Different techniques of geophysical studies were applied in the field of Archaeology through out the world in the recent years which throw a flood of light in the comprehensive research in Archaeology, which also may applied in the search of ancient history of Tamil country and will also be a progressive way to reveal continuous cultural settlements that existed in the state.

\section{(a) Magnetometers}

It is one of the most expensive and at the same time very useful and advanced instrument to measures the local variations in the earth's magnetic field and also 
clearly pictures subsoil surface of the area going to be excavated. The geological counterparts consist of certain iron particles with various variations in the degrees with different kind of magnetic behavior. The surface layers of earth tend to show higher magnetism than deeper materials due its Magnetism and the magnetic survey devices allows to detect some of the most important archaeological objects that is buried under the surface. As far as the state of Tamilnadu is concerned it is a iron rich area where it is possible to identify iron objects in almost all the explored sites pertaining to Megalithic culture. Rocks could also have very different magnetic proprieties depending on the forming conditions and composition. Various geological strategraphic successions like Cenozoic, Mesozoic, Proterozoic, Archaean is seen occurring in Tamilnadu. These rock materials seem to be composed of iron particles which were great resource for the ancient people to manufacture various implements, furnace, kiln etc. The iron furnaces and artefacts identified from various ancient sites like Kodumanal(Erode), Guttur(Dharmapuri) revealed the technical advancement made by the iron smelters around 500 B. $C^{6}$ Innumerable numbers of iron slag picked up from various sites of Tamilnadu also prove the uses of iron in the daily life of ancient man. Hence, the use of magnetometers is very vital in pre-excavation stage by which the artefacts and buried material remains could be accessed easily and can be exposed without any disturbance to their actual nature. But there is also abundance of iron in the actual urban environments, which does not allow the use of magnetic systems, where the anomalies produced by these iron objects could be hundreds or thousands of times bigger than the trace of a buried wall. So the use of this instrument must highly mathematical and instrumental in the process of tracing the ancient history.

\section{(b) Resistivity Meters}

For the amateur archaeologists in the recent years, the most commonly used instrument to study earth's resistance and to identify the buried artefacts is Resistivity meters. The hardware usually consists of a box of electronics mounted on a carrying frame, with wires leading down to a pair of metal spikes that are inserted into the ground. An electric current is passed through the ground and the box measures the resistance to the electrical current passing through the ground, hence the name resistivity meter. The amount of resistance is affected by how much moisture there is in the soil. If there is a lot of moisture in the soil, you will get low resistance as the electric current passes through the wet ground easier. Conversely, if there is little moisture, then there is high resistance to the electric current. This instrument will not be useful in sites like Keezhadi, just few kilometers away from Madurai town in the banks of river Vaigai in Sivagangai district where the presence of structural remains which belongs to various cultural assemblage was found, because the presence of constructions will gradually reduce the moisture as the availability of soil will be less in quantity which will be great obstacle for the instrument to contact with the artefacts seen buried deep into the soil.

\section{(c) Ground Penetrating Radar}

The Ground Penetrating Radar (GPR) is a survey method based on the principles of electromagnetism. ${ }^{7}$ It's a technique used to collect and record information about the earth's subsurface. This technology was employed for many years and it is also common in other scientific fields such as geology, environmental studies, etc. Archaeologists take advantage of the physical and chemical changes within the ground relative to the presence or absence of subterranean items. Using highly sensitive instruments the specialist technician can measure, map, and interpret the data signals, received by the GPR system, into useful information. The greatest advantage of ground penetrating radar methods is that they gather an immense amount of information about the near-surface in a totally non-invasive, nondestructive way, permitting large sites with concealed remains to be viewed and analysed efficiently yet accurately, while also protecting and preserving them. Tamilnadu is the land of Multicultural identities right from the Stone age period to modern historical settlement. The availability of Paleolithic tools from the sites like Attirampakkam, Amirthamangalam, Vadamadurai which is continued with the presence of Mesolithic culture that is evidenced from microlithic tools in the Teri sites of Tuticorin district, Veetur, Thiruvakkarai, Mayilam, Kondagi of Villupuram district in Gingee river valley ${ }^{8}$ and the presence of Neolithic tool assemblage from various sites of the state is an important milestone in the research of prehistoric studies in 
India. Later the presence of Iron ore in the state led to the manufacture of various iron implements used in various activities like plough the land for agriculture, settlement, food, planting of trees etc in daily life initially paved way for the economic prosperity during the megalithic culture. Later after the discovery of script and evolution of kingship in the state, it had witnessed enormous development of the basic structure. So, this continuous process of development had left out countless number of remnants like ancient tools, bones, metal artefacts, potsherds, coins, monuments, architectural features such as walls, midden, and wells, geophysical features such as riverbeds, inscriptions, which is the core source for the archaeologists to go forward with their research in search of the antiquity of Tamilnadu. The application of GPR, especially, in coastal studies is well known and is being widely employed in identifying and tracing various buried structures and facies in the beaches dunes, bars, spits $\mathrm{s}$ well as in sand barriers. ${ }^{9}$ As far as the coastal regions like Kaveripoompattinam (Poombuhar) which was highly portrayed in the later Sangam work called Silpathikaaram is a highly potential area which can yield enormous evidences for socio-cultural life of the ancient Tamils. As it is believed that this region could have been submerged in the coast it is the duty of the marine archaeologists to conduct a deep study to mettle the buried history of well civilized society of early Tamils. Also in the Teri sites of Tuticorin region GPR could play in vital role in unearthing the submerged land where the prehistoric Tamils had led a life with new set of improved culture with tiny artefacts after the man had transformed his life style from hunter-gatherer another pace of culture called Mesolithic culture. In this part GPR plays an important role in enhancing the historical knowledge with scientific informations and proper technical procedure of the state to a great extent. Understanding the transition from one cultural assemblage to other will be somehow an easy task by employing GPR technique as the excavations could be conducted in a non-destructive way without disturbing any artifacts or constructions beneath the surface.

\section{Laser Treatment to Protect Monuments from Pollution}

For the past thousand five hundred years the ancient monuments of Tamilnadu more particularly the
Temples have been disturbed by various natural calamities like earthquake, flood, pollution and by the human carelessness. In this decade due to the increased scientific development which initially paves way for the emergence of various industries, exhaust fumes from the vehicles, fire etc poses a threat to the scientists to protect the monuments from the pollution. Nowadays in the western countries new innovative laser technology system is used to the surface of the monuments by uncovering colours and ornamentation hidden for decades. This new technology is a boon for the archaeologists who work in the restoration and reconstruction of the monuments in Tamilnadu. Most of the ancient temples which are in the remote villages and also the temples under the control of private properties and finally under the control of state government are loosing the beauty as they are decorated with various materials like paint, lime, oil, sandal etc in the intention of decorating them without knowing that they are losing in antiqueness. Apart from the temples other monuments like ancient mosques, churches, jain temples and sculptures, later British monuments like Senate House in University of Madras are also being disturbed to a great extent due to hazardous pollutions and salt air which is blown from the adjacent sea. In this regard Crete's Foundation for Research and Technology in Greece created a system with two laser beams, overlapping in time and space. By utilizing both infrared and ultraviolet frequencies, the laser cleaning left little discoloration on surface material, while preserving the historical layers in the Acropolis of Athens. The monuments should be first scanned with ultrasound and an infrared imaging and spectroscopy system to reveal what lies beneath the upper layer settlement. This technology is useful not only in protecting the monuments from pollution but also correcting the mistakes of past restorers who tried to mend the structures and surfaces with different restoration materials. The monuments should be first scanned with ultrasound and an infrared imaging and spectroscopy system to reveal what lies beneath the upper layer settlement. The laser technology is an important factor in the study of herostones in Tamilnadu. Most of the herostones in the state are seen located in the remote villages with or without inscriptions and sculptural representations. But they were seen lying under the oil, turmeric powder, vermilion and various materials as the herostones 
were venerated as the gods and goddess by the local people. If this laser technology is used in the research of herostone studies it would great effort in revealing the historical sequences of the region and the sociocultural identity of the place where the herostones are located.

\section{Non Destructive Evaluation (NDE) Technique}

The study of Chemistry is unavoidable in the historical research to unfold the historical values of Tamilnadu as many artefacts and materials which are identified during the course of exploration and excavation could be subjected to chemical analysis for reaching nearest dates for the materials and accurately dating the cultural periods. Among the archaeological artefacts, coins plays an important role in reconstructing the ancient history of Tamilnadu as it picturize the social structure, economic prosperity, trade activities, rule of various dynasties, etc. So, making use of the non destructive evaluation technique would be useful in determining the elemental composition of ancient coins, even coins that generally have been considered too corroded. ${ }^{10}$ Analysis of elements and isotopes of the metals in the artifacts would also be able to clearly show the place where the metal was mined as the ores present in that particular region used to have unique composition. This can be combined with historical records of when mines in the area were operating to determine when the coin was likely struck. The results not only help date the coin, but also offer insight into trade and power relationships in the region. In Tamilnadu coins from the Sangam Cholas, Pandyas, Kalabhras, Medieval Cholas, Pandyas, Pallvas, Nayaks, Marathas, Nawabs, Roman coins etc have been identified from various sites shows the social infrastructural development in the state. The X-ray florescence and lead isotope analysis is used for identifying the ores used in the production of the coins. But in the corroded coins this technology is not valuable because the corrosion may suitably affect in dating the coins. For this distressed aspects the polarizing optics and the power newly introduced software technology like X-ray florescence and calibration of mass spectrometer would lead to a fruitful in the analysis of dating coins. The identification of ores in which the coins are made speaks about the mineral enrichment that had existed in the ancient Tamil country and also proves the mettle of economic prosperity flourished in the ancient Tamil country.

\section{Drone}

Drone is an unmanned aerial vehicle technology covers everything from the aerodynamics of the drone, materials in the manufacture of the physical UAV, to the circuit boards, chipset and software which are the brains of the drone. Drones are equipped with different state of the art technology such as infra-red cameras (military UAV), GPS and laser (military UAV). Drones provide a useful lowlevel aerial platform for recording historic buildings, monuments, archaeological sites and landscapes. They can carry a wide variety of sensors including cameras, multi/hyperspectral imaging units, and even laser scanners. Drones can provide dramatic illustrative photographs of sites, but can also be used to create metrically accurate records for survey and conservation work. However, care needs to be taken to ensure drones are used in a way that is safe to both people and the historic fabric being recorded. Drones are controlled | by remote control system also sometimes referred to as a ground cockpit. Drones provide key surveying capabilities and point the way to new excavation sites and it also gives us a wider view of an entire site, helping us to identify possible areas of interest - essentially seeing things that we cannot see clearly from ground level. ${ }^{11}$ It is easy to fly and very quick to use where we just need to insert the battery without mounting or dismantling the drone each time. It is light and easy to transport and very safe. As it is also small and discrete it doesn't scare potential visitors. In recent days many sites in Tamilnadu are being excavated which are belonging to different cultural periods like megalithic (Kodumanal), early historical sites (Keezhadi), historical sites etc. The use of drone in these sites is a major advantage in understanding the landscape and recording the archaeological artifacts and excavated features by capturing of still and video imagery and allowing both real time and off site analysis of the condition. Many of the palaeolithic, megalithic sites and the historical monuments in Tamilnadu which are located in remote areas or dense forests are being vandalized by nature (vegetation) and manmade obstacles. In the sites like Adhichanallur were the condition of the site is optimal for extensive research and excavation, the drones can be used very effectively as they produce aerial mapping and 3D 
landscape modeling with centimeter accuracy. This may lead to unearth the hidden archaeological treasure and prove the antiquity of ancient Tamils lying beneath the earth which is also a debatable one for many years. As far as the palaeolithic research in Tamilnadu is concerned, sites like Gudiyam, Attirampakkam, Amirthamangalam, etc have yielded innumerable number of tools and even yielding till date. The site like Gudiyam which is located in dense forest area has been surveyed and was excavated in later 1960's for a small extent. It is pertinent to mention here that making use of this prominent instrument in the research of this site, may unfold the unknown palaeolithic treasure in the form tools and also would be able to prove that the earliest mankind in India belongs to Tamil origin.

\section{X-Radiography}

$\mathrm{X}$-radiography is an invaluable investigative technique that is non-destructive, quick and - cost effective. It enables the form and structure of an object obscured beneath corrosion layers and burial accretions to be viewed without any physical intervention to that object. When an Iron object is heavily or completely mineralized X-radiography can give valuable inputs which the other technologies could offer. The X-Radiography provides some benefits in the study of metal works like visually recording the shape of the metal, technology implemented in the manufacture of the artifact, present condition of the artifact without any destruction to the materials and also has some long term benefit in recording the deteriorating artifacts. This process will be helpful in the sites like adhichanallur (Tuticorin district), where innumerable metal implements made out of various raw materials have been identified. Keezhadi (Sivagangai district) was excavated recently and it exposed the structure after structure surfacing from under the soil which unfolded the massive scale of ancient urban centre also yielded many iron implements to its credit. Metal objects should be immediately X-rayed in order to provide an archival record of the artifacts and their condition because under various certain circumstances, deterioration may occur quickly. The early identification and dating of the finds from a range of interventions, including evaluations, may contribute to the interpretation of the site and thus inform subsequent action. X-rays will show size, shape and details of construction of the items under examination that will aid object identification as well as contribute to their characterisation, technical description, classification and dating. X-radiography can provide a range of technological information about the manufacture of an object, from details of the microstructure of the metals and alloys employed, whether it was made from sheet metal, wrought or cast, through to details of the construction of complex artefacts. To achieve the maximum information and quality in X-radiographs requires some knowledge of the nature of the assemblage and a rigorous methodology. The first will enable the best orientations and exposures to be selected, while the latter will facilitate good quality images and a clear understanding of the relationship of the image to the original artefacts. Operator skill and experience plays a crucial part in the process. ${ }^{13}$

All the above mentioned techniques were successfully used in the archaeological research by the archaeologists in the western countries. The use of this technologies favour the researchers to conclude the research with fruitful results and with accuracy in dates as the conventional methods in the archaeological research sometimes leads to present unacceptable dates for the artifacts and proper cultural identity to the ancient sites. So the use of the new technologies will be a major upliftment in archaeological research in Tamilnadu which is the land enormous historical values. From the palaeolithic culture to the later historical period the state embodies different cultural variations which could be known from identification of stone tools, burial monuments, metal implements, bone pieces, charcoal, coins, inscription, monuments in the form temples, sculptures, later buildings constructed out of bricks and sandstones etc. These material evidences were the great properties in dating back the cultural history of Tamilnadu to the earliest among all the civilized societies of the world. But the use of the above mentioned technologies is itself in a degraded condition as far the archaeological research in the nation is concerned. The awareness and knowledge of applying these techniques must be imposed among the scholars in the field of archaeology. If these were applied archaeological research in the state would take a new dimension. 


\section{End Notes}

1. Timothy E. LA Tour, Analysis of Rocks using $X$-Ray fluorescence Spectrometry, The Rigaku Journal, vol.6/No.1, Georgia, 1989

2. Karl Wirth, $X$-Ray fluorescence $(X R F)$, Indiana University, Indianapolis

3. $L I D A R$, National Oceanic and Atmospheric Administration (NOAA),Dept. of Commerce, USA, Archived from the original on June 4, 2013.

4. Earth Impact Database (EID), crater beneath canopy, University of NewBrunswick.

5. R. Opitz, Airborne Laserscanning in Archaeology: Maturing Methods and Democratizing Applications, Digital Methods and Remote Sensing in Archaeology, Quantitative Methods in the Humanities and Social Sciences, M. Forte and S. Campana (eds.), Springer International Publishing, Switzerland, 2016

6. B. Sasisekaran, Metallurgy and Metal Industry in Ancient Tamilnadu - An Archaeological Study, Indian Journal of History of Science, 2002

7. Roger Sala, Robert Tamba, Archaeological Geophysics - From Basics to New Perspectives, www.intechopen.com

8. V. Selvakumar, Prehistoric Sites in NorthCentral Tamilnadu, South India, Journal of Physical Anthropology and Human Genetics, Vol.32, No.1, 2013

9. Neal A., Robert C. L., Application of ground penetrating radar (GPR) to sedimentological, geomorphological and geoarchaeological studies in coastal environments in coastal and estuarine environments, Geol. Soc. London Spec. Publ, $175,139-171$.

10. National Institute of Standards and Technology (NIST), Science Daily, May, 2010

11. Alison Dickens, Cambridge Archaeological Unit (CUA), Cambridge, London

12. Guidelines on the X-Radiography of Archaeological Metalwork, English Heritage, Historic England, 2006

13. op.cit 